\title{
a cultura andaluza ante el siglo XXI
}

\section{Salvador Rodríguez Becerra}

Dpto. Antropología Social Universidad de Sevilla

Fundación Machado
Las sociedades europeas viven actualmente en una perplejidad y aparente contradicción, pues mientras se crean formas de convivencia y relaciones supraestatales que merman la soberanía de los estados, los pueblos o sectores de ellos ahondan en sus singularidades y en sus deseos de autogobierno con fórmulas descentralizadoras, autonómicas e, incluso, de independencia. El modelo del estado-nación de fuerte tendencia homogeneizadora se debilita y simultáneamente emergen otras fórmulas que nuclean y estructuran el territorio y abordan la cultura desde ópticas más cercanas al ciudadano. Los conceptos propios del sistema de valores generados por el Estado de los siglos precedentes empiezan a ser sustituidos por los de comunidad, pueblo, sociedad, ciudadanía. Un nuevo tipo de contrato social se está gestando entre los ciudadanos y el Estado; éste, no obstante debe seguir garantizando los derechos sociales e individuales básicos.

Andalucía en el fin del milenio se presenta como una sociedad políticamente autónoma, socialmente cambiante a un ritmo nunca antes conocido y culturalmente más consciente de su singularidad. Dada su especial configuración geográfica y conformación histórica es una de las comunidades de mayor extensión y variedad cultural. Diversos procesos socioeconómicos y políticos desarrollados en las últimas décadas, entre los que cabe citar la emigración masiva, la generalización de las libertades, y por supuesto, la creación de la Comunidad Autónoma por la vía constitucional del artículo I5I de la Constitución Española, han provocado la toma de conciencia de su identidad, unidad y diversidad. Este proceso no puede ocultar nuestro pasado: la existencia del reino musulmán de Granada hasta el siglo XV, la división histórica del territorio de la Comunidad hasta el primer tercio del siglo XIX en cuatro reinos $y$, posteriormente, la división en ocho provincias, y en otras tantas divisiones administrativas (eclesiástica, judicial, militar, universitaria, etc), la conformación de una red de importantes ciudades que han aglutinado y vertebrado tan amplio territorio junto a las numerosas áreas económicas especializadas con unas comunicaciones escasas. Todo ello ha determinado la variada configuración económica, social y cultural de Andalucía.
La toma de conciencia de los andaluces de su unidad y la identificación con el territorio, su pasado cultural, y, por ende, con la Comunidad Autónoma cumple una importante función en la vida de los ciudadanos; así mismo, actúa de control hacia los poderes públicos en el reparto de los bienes en el conjunto del estado. Por contra, la diversidad cultural, tiene a veces aspectos negativos, tales como los localismos y las rivalidades territoriales que es necesario neutralizar, si se exacerban, porque constituyen un factor peligroso para la convivencia. Está comprobado que estas situaciones crean sentimientos de discriminación y victimismo que, aunque no respondan a la realidad objetiva del reparto equitativo de los bienes y servicios, son difíciles de contener.

En los últimos años y coincidiendo con la creación en España de las Comunidades Autónomas se ha producido un reconocimiento paulatino de nuestra cultura que se distancia del tópico. No obstante, nuestra peculiar forma de entender la vida, las relaciones familiares y sociales, el ocio, lo lúdico, las relaciones con los seres sobrenaturales, etc., necesitan incluso de una plena aceptación por parte de los andaluces que destierre los complejos de inferioridad que aún afectan a algunos sectores de la población. Esta puesta en valor de nuestra cultura sin embargo no se está haciendo en todos los casos de una forma crítica, sino apasionada e, incluso, ideologizada.

Las circunstancias medioambientales e históricas han modelado en este territorio un tipo de sociedad y cultura que constituye un inmenso patrimonio cultural, entendido éste como el conjunto de las creaciones de las generaciones pasadas que han dejado testimonios tanto materiales como intelectuales. Este patrimonio (arqueológico, histórico, antropológico, arquitectónico, artístico, medioambiental) es fuente de identidad, por lo que debidamente conservado y rehabilitado constituye motivo de profunda satisfacción para sus depositarios, y a la vez fuente de riqueza, por lo que su adecuada explotación es un poderoso activo en el nuevo milenio. El patrimonio etnológico o antropológico que comprende conocimientos y tecnología tradicionales, formas y usos consuetudinarios, rituales, etc., y que ha sido recien- 
Ningún antidoto mejor que un conocimiento profundo de nuestra cultura, de ahi la responsabilidad del sistema educativo, que debe propiciar una enseñanza equidistante y equilibrada entre el localismo y el universalismo, entre el afecto por lo propio y cercano y el respeto a lo exótico y lejano.

temente incorporado al concepto de patrimonio cultural, constituye un potencial que los andaluces no debemos dilapidar por ignorancia y desidia, y menos bajo la presión de la aparente incompatibilidad entre modernidad y tradición.

El patrimonio debe ser estudiado y conservado por la sociedad andaluza y difundido entre los andaluces, entre los que nos estudian o visitan, y de modo general, entre todos los pueblos y países. Ello conlleva no sólo poner en valor aquellos aspectos que resulten más atractivos o rentables sino, también aquellos recursos y medios que faciliten su conocimiento entre los ciudadanos, principalmente, museos y bibliotecas. El nivel actual de estas instituciones no se corresponde con el alcanzado por la sociedad andaluza en el orden económico ni con sus demandas de ocio y cultura; así mismo, esta tarea tiene que ir acompañada por un continuado apoyo a la investigación cultural. La conservación y difusión del rico y variado patrimonio andaluz ha sido hasta ahora preocupación exclusiva de los poderes públicos que no pueden seguir afrontándolos plenamente por razones presupuestarias. Su mantenimiento y potenciación debe empezar a ser también motivo de preocupación y dedicación de toda la sociedad. Las asociaciones ciudadanas y las entidades privadas deben jugar un papel más importante del que hasta ahora han desempeñado e involucrarse de manera más participativa.

Finalmente, conviene dejar claro, finalmente, que el necesario y deseable progreso de nuestra sociedad debe hacerse a un ritmo que no produzca pérdidas irreparables en la cultura y conflictos sociales. No debemos renunciar a las propias señas de identidad, es decir, preservar las convicciones propias y los modos de entender el mundo, procurando, además, que los ciudadanos sean conscientes del cambio. Los intercambios culturales con otras sociedades deben hacerse en igualdad de condiciones, por lo que a las administraciones corresponde poner los medios necesarios. Para evitar estos posibles males ningún antídoto mejor que un conocimiento profundo de nuestra cultura, de ahí la responsabilidad del sistema educativo, que debe propiciar una enseñanza equi- distante y equilibrada entre el localismo y el universalismo, entre el afecto por lo propio y cercano y el respeto a lo exótico y lejano.

Para preparar la llegada de este tercer milenio, siquiera sea en sus primeras décadas, han reflexionado algunos cientíícos sociales, intelectuales y actores de la cultura sobre cómo será o debería ser la Andalucía del siglo XXI, en función de los fenómenos sociales y culturales en pleno vigencia y otros ya apuntados en este fin de siglo. Sería deseable una sociedad plenamente abierta a otras culturas, que integre a las personas que decidan vivir en ella, sin que ello suponga la pérdida de nuestra identidad; una sociedad en la que todos participen equitativamente de la riqueza; que promocione la diversidad en el respeto mutuo; y que construya un proyecto social en el que la participación activa de la mujer no tenga vuelta atrás. Éste es el modelo de sociedad que queremos para el siglo XXI, y que especificamos en los siguientes objetivos:

a) Profundizar en la definición cultural de Andalucía, a partir de un mejor conocimiento de la cultura andaluza en su unidad y diversidad, evitando su mixtificación, potenciándola entre todos los andaluces y abriéndola a Europa y al Mundo.

b) Promover un mayor conocimiento, protección, difusión y adecuada gestión del patrimonio cultural andaluz con la participación de las sociedad civil y la orientación de las administraciones públicas. La protección del patrimonio debe ser compatible con los adecuados usos para el turismo.

c) Impulsar el diálogo, la tolerancia y la convivencia, incentivando la educación en los valores de la solidaridad y la integración entre los distintos grupos y culturas presentes en la Comunidad Autónoma de Andalucía y creando las condiciones para una adecuada convivencia que haga posible lo que todavía es sólo un deseo, que Andalucía sea una realidad multicultural 